\title{
Effects of thermal acclimation on water loss rate and tolerance in the collembolan Pogonognathellus flavescens
}

\author{
HANS PETTER LEINAA S ${ }^{1}$, SARETTE S L B B ER R and T T VEN L. \\ $\mathrm{CHOW} \mathrm{N} \mathrm{H}^{2}$ \\ ${ }^{1}$ Integrative Biology Group, Department of Biology, University of Oslo, Oslo, Norway and ${ }^{2}$ Centre for Invasion Biology, \\ Department of Botany and Zoology, Stellenbosch University, Matieland, South Africa
}

\begin{abstract}
A few days of thermal acclimation (to $5{ }^{\circ} \mathrm{C}$ versus $15{ }^{\circ} \mathrm{C}$ ) may strongly affect tolerance to drought stress in Collembola. To better understand this phenomenon, the effect of acclimation on water loss rate and its consequence for survival in the species Pogonognathellus flavescens Tullberg (Tomoceridae) is investigated. Acclimation does not affect the water content of hydrated animals but animals exposed to $15{ }^{\circ} \mathrm{C}$ and $76 \%$ relative humidity lose water much faster after having been acclimated to $5{ }^{\circ} \mathrm{C}$ rather than $15{ }^{\circ} \mathrm{C}$. Tolerance to water loss is not affected; in both treatment groups, animals survive up to $40 \%$ loss of the water content recorded when fully hydrated. The percentage water content of hydrated animals decreases with size, which may explain why the proportion of initial water lost appears to be a better predictor for survival than the amount of remaining water. The proportion of initial water lost per unit time is little influenced by size in animals acclimated to $15{ }^{\circ} \mathrm{C}$ but increases with decreasing size in the group at $5{ }^{\circ} \mathrm{C}$, indicating that acclimation affects a physiological protection against water loss.
\end{abstract}

Key words. body water content, desiccation, survival, thermal adaptation.

\section{Introduction}

Water loss is a major challenge for terrestrial life, and especially so for small arthropods. Sensitivity to dry conditions also has implications for species responses to climate change because increasing drought is predicted for many temperate areas (Easterling et al., 2000). Consequently, numerous studies exist reporting on desiccation resistance from physiological and/or ecological points of views (Ring et al., 1990; Hadley, 1994; Zachariassen, 1996; Addo-Bediako et al., 2001; Chown, 2002; Gibbs et al., 2003; Hoffmann et al., 2003).

Much work focusses on the insects, which, with their desiccation resistant cuticles and invaginated tracheal systems, typically tolerate considerable exposure to dry conditions (Hadley, 1994; Chown \& Nicolson, 2004 for review). Both cuticular modifications and alteration of the pattern and rate

\footnotetext{
Correspondence: Hans Petter Leinaas, Integrative Biology Group, Department of Biology, University of Oslo, PO Box 1066, Blindern, N-0316 Oslo, Norway. Tel.: +47 2285 5276; fax: +47 2285 4726; e-mail: h.p.leinaas@bio.uio.no
}

of gas exchange form significant components of the insect response to altered water availability (Zachariassen et al., 1988; Toolson \& Kuper-Simbrón, 1989; Gibbs et al., 1998; White et al., 2007). Springtails also comprise a focus of considerable research in this arena. Because most springtails exchange gasses and thus transpire through the body surface, they are, in general, highly sensitive to changes in the humidity of their surrounding environments (Noble-Nesbitt, 1963; Vannier \& Verdier, 1981; Verhoef \& Prast, 1989; Harrisson et al., 1991; Kærsgaard et al., 2004; Elnitsky et al., 2008). Consequently, variation in drought exposure may have considerable impact on individual performance, and on habitat occupancy of species in relation to drought tolerance (Verhoef \& Witteveen, 1980; Verhoef \& van Selm, 1983; Leinaas \& Sømme, 1984; Leinaas \& Fjellberg, 1985; Hertzberg \& Leinaas, 1998).

Desiccation stress is a function of current, physical conditions. However, the phenotypic response may also be influenced by conditions encountered previously by an individual, as a consequence of acclimation. Indeed, acclimation forms a fundamental part of individual and population responses to fluctuating environments (Kingsolver \& Huey, 1998; Huey 
et al., 1999; Wilson \& Franklin, 2002; Stillman, 2003). Many types of acclimation may theoretically affect drought resistance. Several studies report that drought acclimation may have positive effects on desiccation tolerance in Collembola (Sjursen et al., 2001; Holmstrup et al., 2002; Elnitsky et al., 2008). However, the substantial influence of temperature on desiccation stress (Hadley, 1994) suggests that the effects of thermal acclimation require closer attention than they have enjoyed to date (Gibbs et al., 1998; Terblanche et al., 2005).

On the basis of such arguments, Chown et al. (2007) report the effects of thermal acclimation on drought tolerance in a comparison of indigenous and invasive collembolan species on sub-Antarctic Marion Island ( $46^{\circ} 54^{\prime} \mathrm{S}, 37^{\circ} 45^{\prime} \mathrm{E}$ ). It is demonstrated that surprisingly strong effects of thermal acclimation are exerted on survival time under desiccation stress, and that invasive species differ from indigenous ones in the form of the phenotypic plasticity that they show (Chown et al., 2007). More specifically, the invasive species typically have longer survival times after acclimation to higher than to lower temperatures, whereas the indigenous species show the opposite pattern.

To better understand the evolution of such differential acclimation effects, an improved understanding of the processes underlying them is necessary. As a first approach, the present study focuses on some major differences in possible mechanisms involved: the observed acclimation effects may not only involve changes in the tolerance of absolute water loss and/or alteration of transpiration rates (Chown, 1993; Gibbs et al., 1998), but also the water content of hydrated animals might be affected by the acclimation temperature. The different mechanisms are not mutually exclusive and, in the present study, these three possibilities are examined in one selected species. Moreover, an analysis of size-dependent water loss rate after acclimation to different temperatures is undertaken to determine the extent to which physical or physiological processes might be involved in any change in transpiration rate. Both factors may be important in protection against desiccation in Collembola (Verhoef \& Witteveen, 1980; Verhoef \& Prast, 1989).

To address these questions, the effects of temperature acclimation on water loss rates and dehydration tolerance are investigated in one of the invasive species studied previously, namely Pogonognathellus flavescens Tullberg (Tomoceridae). This species shows an especially strong effect of acclimation at $5{ }^{\circ} \mathrm{C}$ versus $15{ }^{\circ} \mathrm{C}$. When subsequently exposed to $15{ }^{\circ} \mathrm{C}$ and $76 \%$ relative humidity $(\mathrm{RH})$, the latter acclimation results in an almost twice as long survival time compared with the former (Chown et al., 2007). The present study therefore focuses on these treatments.

\section{Materials and methods}

Pogonognathellus flavescens is widely distributed in temperate regions of the Holarctic, usually in damp habitats (Gisin, 1960; Fjellberg, 1980). It was introduced accidentally to sub-Antarctic Marion Island (46 54'S, $37^{\circ} 45^{\prime} \mathrm{E}$ ) and subsequently has become invasive (Chown et al., 2002).
The present study was conducted at Marion Island in April 2004.

Soil samples from a site with a high density of the species were collected and returned to the laboratory within $2 \mathrm{~h}$. There, two groups of animals were gently sorted by aspirator and transferred to $30-\mathrm{mL}$ plastic vials that had wet Plasterof-Paris bases, and supplied with approximately $2-3 \mathrm{~cm}$ of wetted, loose natural substrate (litter, moss, etc.) in which the animals sought shelter. The vials were closed by lids and were regarded to have constant saturated humidity throughout the acclimation period. In these vials, the animals were held at $5{ }^{\circ} \mathrm{C}$ and $15{ }^{\circ} \mathrm{C}$, respectively, in climate chambers (Labcon, Johannesburg, South Africa, accurate to $\pm 1{ }^{\circ} \mathrm{C}$ ) for 1 week, corresponding to the acclimation treatments in our previous experiment (Chown et al., 2007).

Acclimation effects on water loss rate and survival were tested at $15{ }^{\circ} \mathrm{C}$ and constant $\mathrm{RH}$ of $76 \%$, which was maintained using a saturated $\mathrm{NaCl}$ solution. The animals were kept individually in small (diameter $10 \mathrm{~mm}$, height $5 \mathrm{~mm}$ ) cages of fine-meshed stainless steel net. The desiccating conditions were created in sealed $300-\mathrm{mL}$ plastic vials filled with $70 \mathrm{~mL}$ of saturated $\mathrm{NaCl}$. Inside each vial, a smaller (diameter $3 \mathrm{~cm}$, height $7 \mathrm{~cm}$ ) plastic tube was inverted to function as a support for the small stainless steel cages to prevent the animals from coming into contact with the salt solution. Prior to the experiment, the cages were washed in alcohol and air-dried.

Before being placed into the desiccation vials, the cages were weighed alone and with the acclimated animals added. Each trial included eight to 12 individually caged animals. As soon as an animal had been transferred to a cage, and prior to weighing, the cage was kept on an everted, small Petri dish lid $(5.5 \mathrm{~cm})$ that was placed on wet filter paper inside a box $(17 \times 11 \times 6 \mathrm{~cm})$ at $15{ }^{\circ} \mathrm{C}$ to minimize water loss. The balance housing of a Metler Toledo UMX2 (Metler Toledo, Switzerland) was placed inside an earthed Perspex chamber. During the weighing of hydrated animals, the chamber was kept humid by moistened filter paper. As a result of this standardized handling and the fact that $P$. flavescens was found to be relatively drought resistant compared with the other species studied (Chown et al., 2007), the values recorded prior to experimental manipulation were considered to be reasonable estimates of the mass of fully hydrated animals (hereafter referred to as hydrated individuals).

After the initial weighing, the cages were placed into the desiccation chambers at $15{ }^{\circ} \mathrm{C}$. Water loss rates and survival were determined at approximately 2 -h intervals, commencing at $4 \mathrm{~h}$ (time recorded in minutes). For each recording, cages were removed from the desiccating conditions and quickly transferred to the balance (which was conditioned by filter paper moistened with saturated $\mathrm{NaCl}$ solution) and weighed. Survival status was then assessed visually (under a stereo microscope). Individuals not showing any sign of movement, not even with their antenna (and lying on their sides), were scored as dead (Chown et al., 2007). The animals were then dried to constant mass over silica gel and weighed again. Final water content was estimated as final wet mass minus dry mass. Because of differential survival, the desiccation experiment was run in two parts. The first part included both acclimation 
treatments and lasted for $8 \mathrm{~h}$. At that time, almost all the animals acclimated to $5{ }^{\circ} \mathrm{C}$ but none acclimated to $15{ }^{\circ} \mathrm{C}$ had died. Therefore, to describe the survival of animals acclimated to $15{ }^{\circ} \mathrm{C}$, a second experiment with this acclimation only was run for $10-15 \mathrm{~h}$. Because this second experiment dealt with a different set of animals and only one acclimation treatment, these animals were only included in analyses that required data on both living and dead animals from both acclimations (i.e. effect of water loss on survival, and survival as a function of time). Tests on the effects of acclimation on dry mass/hydrated water content ratio, and on the size-dependent water loss ratio, were performed on animals from the first experiment.

Initial body water content was estimated by subtracting dry from wet mass, and expressed as the proportion of original (wet) mass (Hadley, 1994). The effects of dry mass and acclimation on the water content of hydrated animals were compared between animals from the first experimental part. A general linear model was used for the test with arcsine transformation of the fraction of water as the response variable.

To determine water loss tolerance, both live and dead individuals from all time periods for each acclimation treatment were pooled, and the degree of desiccation was calculated for each individual in two ways: (i) the proportion of water lost was calculated as initial water content minus final water content and divided by initial water content and (ii) final (relative water) content was calculated as final water content divided by dry mass. Both measures have been used previously to determine water loss tolerance (Hadley, 1994, Chown \& Klok, 2003). Logistic regression was used in each of the four cases (i.e. two tolerance measures for each of two acclimation treatments) to determine the extent to which each measure could predict the status (live or dead) of the animals.

Because the proportion of water lost provided the best predictor of status (see Results), this measure was used in a further analysis to examine the effects of time and acclimation treatment on water loss, applying a general linear model with arcsine transformed proportional water loss as the response variable.

Finally, patterns of how acclimation affected the relation between water loss rate and animal size were analysed. If desiccation is mainly controlled by physiological mechanisms the relative water loss (i.e. water loss/initial water content) per unit time would presumably be less strongly influenced by the increasing surface area to volume ratio with decreasing size versus when water loss is mainly controlled by cuticular structures. Thus, if acclimation at $5{ }^{\circ} \mathrm{C}$ weakened a physiological protection, it was expected that the size dependence of the rate of relative water loss rate would increase. To investigate this, the rate of relative water loss against size was plotted. Body mass is related strongly to hydrated water content. Indeed, because the present study focuses on the fraction of water lost, size is expressed as the initial water content of (hydrated) animals. Thus, because the predictor variable (initial water content) is included in the response variable (water loss rate/initial water content), any analysis would be confounded. Consequently, in the statistical analysis, the comparison among acclimation groups was instead made by investigating the relationships between absolute water loss rate and initial water content for each of the acclimation treatments. The relationship between absolute water loss rate $(y)$ and size $(x)$ may be described by a linear model: $y=a+b x$ (see Results). Thus, the rate of relative water loss may be expressed as: $y / x=b+a / x$. This means that the intercepts of the absolute water loss curves reflect how fast the relative water loss decreases with size (i.e. at small sizes, differences in the constant $a$ (intercept) have a substantial effect on $y / x$ but, with increasing size, $y / x$ approaches the constant $b$ (slope). If the intercept approaches zero, this means that the rate of relative water loss approaches a constant value (i.e. independent of the area to volume ratio). (With $a=0$, then $y / x=b$ for any value of $x$ ). The slope estimates the value to which the relative water loss response curves approaches asymptotically with increasing size.

A general linear model was used to compare the effect of size between the treatment groups. Transformation of data was not required (Levene test for equal variance: $F^{1,83}=0.838$, $P=0.36$ ). During the $8 \mathrm{~h}$ of drought exposure included in this comparison, mortality only occurred among the animals acclimated to $5{ }^{\circ} \mathrm{C}$ (see Results). To avoid over-estimating water loss in this acclimation group as a result of a possible increased water loss rate after death, a conservative test was performed including only animals that had survived the experiment.

\section{Results}

Dry mass and proportional water content showed a distinct negative relationship in the hydrated animals (Fig. 1). However,

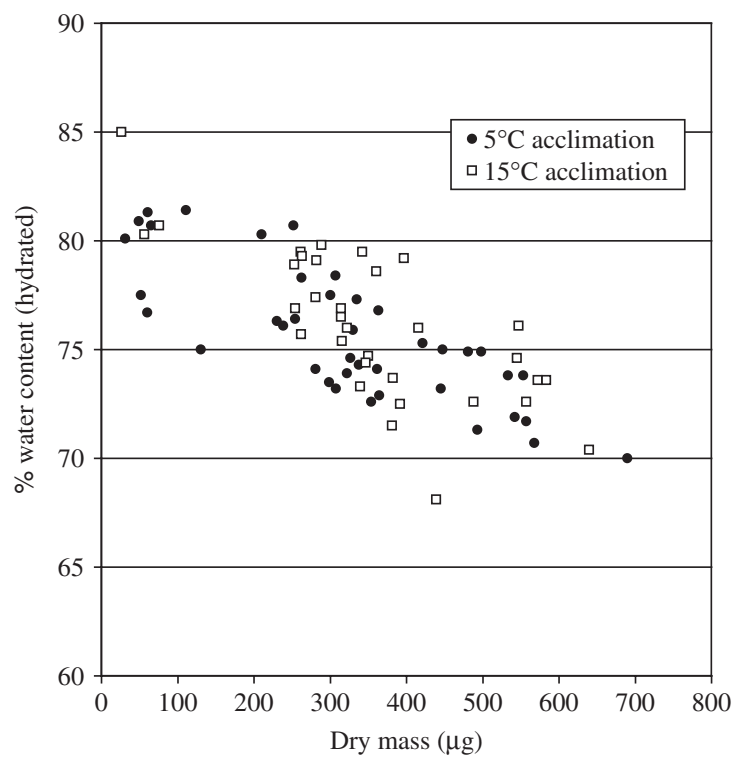

Fig. 1. Percentage water content of fully hydrated Pogonognathellus flavescens as a function of body dry mass and acclimation treatments. General linear model (analysis of covariance), with arcsine transformation of fraction of initial water content as response variable, showed a highly significant effect of dry mass $\left(F_{1,63}=27.5\right.$; $P<0.0001)$. However, there was neither an effect of acclimation $\left(F_{1,63}=2.1 ; P=0.15\right)$, nor any significant time $\times$ acclimation interaction $\left(F_{1,63}=0.01 ; P=0.75\right)$. 
this relationship did not differ between acclimation treatments, showing that temperature did not affect the water content of hydrated animals.

Survival appeared to be much more closely related to the fraction of body water that was lost during the experiment (Fig. 2a) than to the remaining water content relative to dry mass (Fig. 2b). Accordingly, the logistic regression of the former relation had a much higher $R^{2}$ than the latter for both acclimations (Fig. 2). Consequently, the proportion of water lost was retained as a major variable for analysis. It indicated a threshold for mortality of approximately $40 \%$ body water loss at both acclimation temperatures. Thus, we found no effect of acclimation temperature on water loss tolerance (i.e. dehydration tolerance; Hadley, 1994).

Our study confirmed previous results (Chown et al., 2007) that animals acclimated to $15{ }^{\circ} \mathrm{C}$ survived much longer than those acclimated to $5{ }^{\circ} \mathrm{C}$ (Fig. 3). The former group had much lower water loss across time, an effect that was highly significant (Table 1). The same result was also evident when only analysing animals from the 4-h period prior to any mortality (Table 1), when animals acclimated to $5{ }^{\circ} \mathrm{C}$ and $15{ }^{\circ} \mathrm{C}$ on average had lost $25.2 \%$ and $17.7 \%$ of the initial water, respectively. Figure 3 also shows that the water loss rate of the animals acclimated to $15{ }^{\circ} \mathrm{C}$ appeared to increase and become more variable towards the end of the experiment when most animals had died, which is probably a main contribution to the significant time $\times$ acclimation interaction (Table 1). Increasing water loss rate in these animals after death is suggested by the significantly higher water loss rate (per unit time) in animals exposed to drought for $14-15 \mathrm{~h}$, when all except one died, compared with the animals from the first part (4-8 h) of the study when all survived (general linear model: effect of time period: $F^{1,31}=15.8 ; P=0.019$; effect of size $F^{1,31}=9.92$; $P<0.0001)$.

The relative water loss rate appeared generally higher in the animals acclimated to $5{ }^{\circ} \mathrm{C}$. In addition, the difference between treatment as well as variation within treatment decreased with size (Fig. 4). The absolute water loss rates for both acclimations were fairly well described by linear models: $5{ }^{\circ} \mathrm{C}$ acclimation: water loss rate $=0.380+0.00066 \times$ size; $R^{2}=0.61$. $15{ }^{\circ} \mathrm{C}$ acclimation: water loss rate $=0.046+0.00064 \times$ size; $R^{2}=0.66$. Figure 4 shows that the animals acclimated to $5{ }^{\circ} \mathrm{C}$ that died during the experiment had higher rates of water loss than those that survived. However, the conservative test in Table 2, only including the latter, is likely to underestimate the direct acclimation effects because the excluded animals that died during the experiment probably had the highest water loss rate also in the living state. The results nevertheless clearly demonstrate that a substantial part of the acclimation effect is a result of the differential water loss rate in living animals. The difference in intercept was highly significant, as was the effect of size. On the other hand, the lack of a significant size $\times$ acclimation interaction shows that the slopes did not differ between treatments (i.e. the response curves for absolute water loss form two parallel lines). This means that even when excluding all the animals acclimated


Fig. 2. Survival in relation to drought stress in animals acclimated to $5{ }^{\circ} \mathrm{C}$ and $15{ }^{\circ} \mathrm{C}$, expressed both as (a) percentage loss of initial (hydrated) body water (logistic regression: $R^{2}=1.000 ; \chi^{2}=40.49$, d.f. $=1, P<0.0001$ and $R^{2}=0.907 ; \chi^{2}=68.50$, d.f. $=1, P<0.0001$, for animals acclimated to $5{ }^{\circ} \mathrm{C}$ and $15^{\circ} \mathrm{C}$, respectively) and (b) as remaining body water/dry mass (logistic regression: $R^{2}=0.369 ;{ }^{2}=14.95$, d.f. $=1, P=0.0001$ and $R^{2}=0.626 ;{ }^{2}=47.30$, d.f. $=1, P<0.0001$ for animals acclimated to $5{ }^{\circ} \mathrm{C}$ and $15{ }^{\circ} \mathrm{C}$, respectively). 



Fig. 3. Percent of initial (fully hydrated) water content remaining in Pogonognathellus flavescens after drought exposure $\left(15^{\circ} \mathrm{C} ; 76 \%\right.$ $\mathrm{RH})$ for different periods of time. (a) Animals acclimated to $5{ }^{\circ} \mathrm{C}$. (b) Animals acclimated to $15{ }^{\circ} \mathrm{C}$. Filled symbols represent animals that were still alive at the end of treatment. Open symbols represent animals that were dead at the end of treatment. Dashed lines indicate $40 \%$ water loss.

to $5{ }^{\circ} \mathrm{C}$ that died during the experiment, the relative water loss of the two treatments (Fig. 4) differed clearly but converged asymptotically with size. Moreover, the estimated intercept in the animals acclimated to $15{ }^{\circ} \mathrm{C}$ was very close to zero, indicating that their rate of relative water loss was little affected by size (Fig. 4), especially when disregarding the smallest animals.

\section{Discussion}

The present study shows that the relative amount of water content in fully hydrated animals decreases with increasing body size, reflecting the possibility that other storage components, such as lipids and carbohydrates, increase relative to water content with increasing size. Similar results are reported for other insects (Edney, 1977; Hadley, 1994). The size dependency of proportional body water might explain why the proportion of initial water lost appears to be a more relevant predictor for survival and thus of desiccation tolerance than the amount of remaining water (relative to body dry weight).

Although a large effect of acclimation on survival time in P. flavescens is reported by Chown et al. (2007), it is not clear to what extent this is the result of changes in water loss tolerance and water loss rates, nor could the possibility be excluded that acclimation affects the amount of water in hydrated animals. The present study demonstrates clearly that the only significant effect is that the animals acclimated to $5{ }^{\circ} \mathrm{C}$ have much higher water loss rates. A reduction in the rate of water loss is a typical response to drier conditions in many arthropods (Edney, 1977; Zachariassen et al., 1988; Hadley, 1994; Chown \& Nicolson, 2004) and is repeatedly obseved even within species (Hadley \& Massion, 1985; Rourke, 2000; Terblanche et al., 2006; Parkash et al., 2008). Intraspecific variation may reflect fixed differences within (Hoffmann et al., 2001) and/or between populations (Karan \& Parkash, 1998; Hoffmann et al., 2003) but phenotypic plasticity expressed as a response to acclimation may also be important. The effects of drought acclimation are well documented for both insects (Hoffmann, 1990; Benoit et al., 2007) and Collembola (Sjursen et al., 2001; Holmstrup et al., 2002; Elnitsky et al., 2008). In the present study, however, a surprisingly pronounced effect on water loss rates of a short-term thermal acclimation is shown. Only a few studies have investigated thermal acclimation effects on water loss rates and the results obtained are mixed. In some cases, no effect is documented, such as in Drosophila mojavensis (Gibbs et al., 1998) and in the chrysomelid Chirodica chalcoptera (Terblanche et al., 2005), whereas, in others, clear effects are found. Thus, acclimation to high $\left(20^{\circ} \mathrm{C}\right)$ versus low $\left(17^{\circ} \mathrm{C}\right)$ temperatures results in a decline in cuticular permeability in Drosophila pseudoobscura (Toolson, 1982; Toolson \& KuperSimbrón, 1989), whereas, in Drosophila melanogaster, acclimation to summer conditions generally results in an increase in survival under desiccating conditions (Hoffmann et al., 2005).

The present study reveals a strong variation of the acclimation effect with size, and the results suggest that larger animals having a water content of as much as $2000 \mu \mathrm{g}$ in the hydrated state would be little affected by the acclimation treatment. Apparently, no similar size-dependent effect of acclimation has previously been reported.

The results are consistent with the idea that a physiological control of water loss present in the animals acclimated to $15{ }^{\circ} \mathrm{C}$ is greatly reduced by acclimation to $5{ }^{\circ} \mathrm{C}$. In particular, the effect of acclimation to $15{ }^{\circ} \mathrm{C}$ protects sensitive smaller animals against rapid water loss. Such size dependence can hardly be explained simply by physical protection of the cuticle. By contrast, animals acclimated to $5{ }^{\circ} \mathrm{C}$ diverge much less from the expectation of simple physical drying (Harrisson 
Table 1. General linear model (analysis of covariance) for effects of acclimation on water loss during a desiccation exposure in Ponognathellus flavescens (response variable $=$ arcsine transformation of the fraction of initial body water lost).

\begin{tabular}{|c|c|c|c|c|}
\hline Source & d.f. & SS & $F$ & $P$ \\
\hline \multicolumn{5}{|c|}{ Effect on water loss throughout the whole experiment } \\
\hline Time & 1,91 & 0.6459 & 43.85 & $<0.0001$ \\
\hline Acclimation & 1,91 & 0.7012 & 47.61 & $<0.0001$ \\
\hline Time $\times$ acclimation & 1,91 & 0.0628 & 4.628 & 0.03 \\
\hline \multicolumn{5}{|c|}{ Water loss during the first $4 \mathrm{~h}$ of drought exposure } \\
\hline Acclimation & 1,32 & 0.0889 & 17.40 & 0.0003 \\
\hline
\end{tabular}

Neither time (within the very narrow sampling range of $237-251 \mathrm{~min})$ nor a time $\times$ acclimation interaction were significant $(P=0.15$ and $P=0.61$, respectively).

et al., 1991). Physiological changes in the epidermis underlying the cuticle and in the concentration of the body fluids are reported to affect desiccation in springtails (Verhoef \& Witteveen, 1980; Verhoef \& Prast, 1989; Holmstrup et al., 2001; Kærsgaard et al., 2004). The existence of a physiological protection mechanism is also consistent with an apparent increase in water loss after death, most clearly seen in the animals acclimated to $15{ }^{\circ} \mathrm{C}$. What this mechanism might comprise requires further exploration.

Warm conditions are often associated with dry periods in temperate areas, where the species occurs naturally, and even at constant humidity, drought stress is much higher at $15{ }^{\circ} \mathrm{C}$



Fig. 4. Effects of thermal acclimation and body size on the rate of relative water loss in Pogonognathellus flavescens. Body size is expressed as initial water content (in fully hydrated animals) and the rate of relative water loss as the fraction of initial water lost per minute. Acclimation at $5{ }^{\circ} \mathrm{C}$ : open circles, died during experiment; closed circles, survivors. Acclimation at $15{ }^{\circ} \mathrm{C}$ : squares, all survived. than at $5{ }^{\circ} \mathrm{C}$ (Chown et al., 2007). Consequently, an acclimation temperature of $15{ }^{\circ} \mathrm{C}$ might be received as a signal for increased need of protection against desiccation. However, the underlying mechanism for physiological protection is likely to have been established independent of acclimation, and the animals may also profit from the physiological protection being turned off, or reduced, when it is less likely to be needed (i.e. at low temperatures). The fact that closely-related collembolan species living in habitats of contrasting humidity differ correspondingly in drought tolerance suggests that the protection is costly (Leinaas \& Fjellberg, 1985; Bauer \& Christian, 1993; Hertzberg \& Leinaas, 1998) and that a reduction of these costs should be advantageous. This argument is consistent with the differential response to the same thermal acclimation regime in indigenous versus invasive alien species at Marion Island (Chown et al., 2007), with the former species being adapted to a much cooler and more humid environment than the European areas from where the invasive species are assumed to originate (Chown et al., 2007). Moreover, the acclimation effect in the invasive species might be more general than is suggested by the investigation of this single species. In their study, Chown et al. (2007) report a similar thermal acclimation effect of survival of desiccation in two distantlyrelated invasive species: (i) the tomocerid, which is the subject of the present study and (ii) the isotomid species Isotomurus cf. palustris. Thus, improved survival of desiccation after high

Table 2. General linear model (analysis of covariance) for the effects of body size (initial water content) and acclimation on water loss rates in Ponognathellus flavescens.

\begin{tabular}{lllc}
\hline Parameter & Estimate & SE & $P$ \\
\hline Intercept $\left(15{ }^{\circ} \mathrm{C}\right)$ & 0.046 & 0.09 & 0.64 \\
Acclimation & 0.27 & 0.05 & $<0.0001$ \\
Size (initial water) & 0.00065 & 0.00008 & $<0.0001$ \\
Size $\times$ acclimation & 0.00003 & 0.00014 & 0.81 \\
\hline
\end{tabular}

Parameters were estimated, on animals exposed to drought for $4-8 \mathrm{~h}$, excluding animals (acclimated to $5{ }^{\circ} \mathrm{C}$ ) that died during the experiment. 'Intercept $\left(15^{\circ} \mathrm{C}\right)$ ' tests the probability that the response curve of this acclimation treatment has an intercept $=0$. 'Acclimation' tests difference in intercept between the two treatment groups. 'Size' shows the general effect of size for both acclimations, whereas 'size $\times$ acclimation' tests differences in slopes between the two response curves. $F^{3,58}=38.7 ; P<0.0001$. 
temperature acclimation might be more widespread in springtails that have become invasive, although further investigations of indigenous and invasive species in the same habitats and areas will be required to establish whether this is the case. Certainly, the suggestion is in accordance with predictions, made on the basis of investigations of other taxa, proposing that invasive species have characteristics that promote their establishment and spread in a given area (Richardson \& Pyšek, 2006; Chown \& Gaston, 2008).

In $P$. flavescens, thermal acclimation appears to affect an active physiological protection against water loss. However, in other collembolan families, structural modifications of areas covered by epicuticular wax may be a more important aspect of drought resistance than in P. flavescens (Lawrence \& Massoud, 1973; Leinaas \& Fjellberg, 1985; H. P. Leinaas, unpublished results). Such lineage-specific differences are likely to have consequences for how thermal acclimation may affect drought resistance, and thus emphasize the importance of future comparative studies that aim to obtain general knowledge about the role of phenotypic plasticity in the response to environmental changes in these animals.

\section{Acknowledgements}

We are grateful to Erika Nortje for assistance in field sampling and to Karl Erik Zachariassen and two anonymous referees for their helpful comments on the manuscript. This work was supported by a South African National Research Foundation/Norwegian Research Council Science Liaison Grant.

\section{References}

Addo-Bediako, A., Chown, S.L. \& Gaston, K.J. (2001) Revisiting water loss in insects: a large scale view. Journal of Insect Physiology, 47, 1377-1388.

Bauer, R. \& Christian, E. (1993) Adaptation of three springtail species to granite boulder habitats (Collembola). Pedobiologia, 37, 280290.

Benoit, J.B., Lopez-Martinez, G., Michaud, M.R. et al . (2007) Mechanisms to reduce dehydration stress in larvae of the Antarctic midge, Belgica antarctica. Journal of Insect Physiology, 53, 656-667.

Chown, S.L. (2002) Respiratory water loss in insects. Comparative Biochemistry and Physiology A, 133, 791-804.

Chown, S.L. (1993) Desiccation resistance in six sub-Antarctic weevils (Coleoptera: Curculionidae): humidity as an abiotic factor influencing assemblage structure. Functional Ecology, 7, 318-325.

Chown, S.L. \& Gaston, K.J. (2008) Macrophysiology for a changing world. Proceedings of the Royal Society of London Series B, Biological Sciences, 275, 1469-1478.

Chown, S.L. \& Klok, C.J. (2003) Water balance characteristics respond to changes in body size in sub-Antarctic weevils. Physiological and Biochemical Zoology, 76, 634-643.

Chown, S.L. \& Nicolson, S.W. (2004) Insect Physiological Ecology. Mechanisms and Patterns. Oxford University Press, U.K.

Chown, S.L., McGeoch, M.A. \& Marshall, D.J. (2002) Diversity and conservation of invertebrates on the sub-Antarctic Prince Edward Islands. African Entomology, 10, 67-82.
Chown, S.L., Slabber, S., McGeoch, M.A. et al. (2007) Phenotypic plasticity mediates climate change responses among invasive and indigenous arthropods. Proceedings of the Royal Society of London Series B, Biological Sciences, 274, 2531-2537.

Easterling, D.R., Meehl, G.A., Parmesan, C. et al. (2000) Climate Extremes: Observations, Modeling, and Impacts. Science, 289, 2068-2074.

Edney, E.B. (1977) Water Balance in Land Arthropods. Springer, Germany.

Elnitsky, M.A., Benoit, J.B., Denlinger, D.L. \& Lee, R.E. (2008) Desiccation tolerance and drought acclimation in the Antarctic collembolan Cryptopygus antarcticus. Journal of Insect Physiology, 54, 1432-1439.

Fjellberg, A. (1980) Identification Keys to Norwegian Collembola. Norsk Entomologisk Forening, Norway.

Gibbs, A.G., Louie, A.K. \& Ayala, J.A. (1998) Effects of temperature on cuticular lipids and water balance in a desert Drosophila: is thermal acclimation beneficial? Journal of Experimental Biology, 201, 71-80.

Gibbs, A.G., Fukuzato, F. \& Matzkin, L.M. (2003) Evolution of water conservation mechanisms in Drosophila. Journal of Experimental Biology, 206, 1183-1192.

Gisin, H. (1960) Collembolenfauna Europas. Museum Histoire Naturelle, Switzerland,.

Hadley, N.F. (1994) Water Relations of Terrestrial Arthropods. Academic Press, San Diego, California.

Hadley, N.F. \& Massion, D.D. (1985) Oxygen consumption, water loss and cuticular lipids of high and low elevation populations of the grasshopper Aeropedellus clavatus (Orthoptera: Acrididae). Comparative Biochemistry and Physiology A, 80, 307-311.

Harrisson, P.M., Rothery, P., Block, W. (1991) Drying processes in the Antarctic collembolan Cryptopygus antarcticus (Willem). Journal of Insect Physiology, 37, 883-890.

Hertzberg, K. \& Leinaas, H.P. (1998) Drought stress as a mortality factor in two pairs of sympatric species of Colembola at Spitsbergen, Svalbard. Polar Biology, 19, 302-306.

Hoffmann, A. (1990) Acclimation for desiccation resistance in Drosophila melanogaster and the association between acclimation responses and genetic variation. Journal of Insect Physiology, 36, 885-891.

Hoffmann, A.A., Hallas, R., Sinclair, C. \& Mitrovski, P. (2001) Levels of variation in stress resistance in Drosophila among strains, local populations, and geographic regions: patterns for desiccation, starvation, cold resistance, and associated traits. Evolution, 55, 1621-1630.

Hoffmann, A.A., Hallas, R.J., Dean, J.A. \& Schiffer, M. (2003) Low potential for climatic stress adaptation in a rainforest Drosophila species. Science, 301, 100-102.

Hoffmann, A.A., Shirriffs, J. \& Scott, M. (2005) Relative importance of plastic $v s$ genetic factors in adaptive differentiation: geographical variation for stress resistance in Drosophila melanogaster from eastern Australia. Functional Ecology, 19, 222-227.

Holmstrup, M., Hedlund, K. \& Boriss, H. (2002) Drought acclimation and lipid composition in Folsomia candida: implications for cold shock, heat shock and acute desiccation stress. Journal of Insect Physiology, 48, 961-970.

Holmstrup, M., Sjursen, H., Ravn, H. \& Bayley, M. (2001) Dehydration tolerance and water vapour absorption in two species of soil-dwelling Collembola by accumulation of sugars and polyols. Functional Ecology, 15, 647-653.

Huey, R.B., Berrigan, D., Gilchrist, G.W. \& Herron, J.C. (1999) Testing the adaptive significance of acclimation: a strong inference approach. American Zoologist, 39, 323-336. 
Kærsgaard, C.W., Holmstrup, M., Malte, H. \& Bayley, M. (2004) The importance of cuticular permeability, osmolyte production and body size for the desiccation resistance of nine species of Collembola. Journal of Insect Physiology, 50, 5-15.

Karan, D. \& Parkash, R. (1998) Desiccation tolerance and starvation resistance exhibit opposite latitudinal clines in Indian geographical populations of Drosophila kikkawai. Ecological Entomology, 23, 391-396.

Kingsolver, J.G. \& Huey, R.B. (1998) Evolutionary analyses of morphological and physiological plasticity in thermally variable environments. American Zoologist, 38, 545-570.

Lawrence, P.N. \& Massoud, Z. (1973) Cuticle structure in the Collembola (Insecta). Revue d'Écologie et de Biologie du Sol, 10, 77-101.

Leinaas, H.P. \& Fjellberg, A. (1985) Habitat structure and life history strategies of two partly sympatric and closely related, lichen feeding collembolan species. Oikos, 44, 448-458.

Leinaas, H.P. \& Sømme, L. (1984) Adaptations in Xenylla maritima and Anurophorus laricis (Collembola) to lichen habitats on alpine rocks. Oikos, 43, 197-206.

Noble-Nesbitt, J. (1963) Transpiration in Podura aquatica L. (Collembola, Isotomidae) and the wetting properties of its cuticle. Journal of Experimental Biology, 40, 681-700.

Parkash, R., Rajpurohit, S. \& Ramniwas, S. (2008) Changes in body melanisation and desiccation resistance in highland vs. lowland populations of D. melanogaster. Journal of Insect Physiology, 54, 1050-1056.

Richardson, D.M. \& Pyšek, P. (2006) Plant invasions: merging the concepts of species invasiveness and community invasibility. Progress in Physical Geography, 30, 409-431.

Ring, R.A., Block, W., Sømme, L. \& Worland, M.R. (1990) Body water content and desiccation resistance in some arthropods from subantarctic South Georgia. Polar Biology, 10, 581-588.

Rourke, B.C. (2000) Geographic and altitudinal variation in water balance and metabolic rate in a California grasshopper, Melanoplus sanguinipes. Journal of Experimental Biology, 203, 2699-2712.

Sjursen, H., Bayley, M. \& Holmstrup, M. (2001) Enhanced drought tolerance of a soil-dwelling springtail by pre-acclimation to a mild drought stress. Journal of Insect Physiology, 47, 1021-1027.

Stillman, J.H. (2003) Acclimation capacity underlies susceptibility to climate change. Science, 301, 65.

Terblanche, J.S., Sinclair, B.J., Klok, C.J. et al. (2005) The effects of acclimation on thermal tolerance, desiccation resistance and metabolic rate in Chirodica chalcoptera (Coleoptera: Chrysomelidae). Journal of Insect Physiology, 51, 1013-1023.

Terblanche, J.S., Klok, C.J., Krafsur, E.S. \& Chown, S.L. (2006) Phenotypic plasticity and geographic variation in thermal tolerance and water loss of the tsetse Glossina pallidipes (Diptera: Glossinidae) implications for distribution modelling. American Journal of Tropical Medicine and Hygiene, 74, 786-794.

Toolson, E.C. (1982) Effects of rearing temperature on cuticle permeability and epicuticular lipid composition in Drosophila pseudoobscura. Journal of Experimental Zoology, 222, 249-253.

Toolson, E.C. \& Kuper-Simbrón, R. (1989) Laboratory evolution of epicuticular hydrocarbon composition and cuticular permeability in Drosophila pseudoobscura: effects of sexual dimorphism and thermal-acclimation ability. Evolution, 43, 468-473.

Vannier, G. \& Verdier, B. (1981) Critères écophysiologiques (transpiration, respiration) permettant de séparer une espèce souterraine d'une espèce de surface chez les insectes Collemboles. Revue d'Écologie et de Biologie du Sol, 18, 531-549.

Verhoef, H.A. \& Prast, J.E. (1989) Effects of dehydration on osmotic and ionic regulation in Orchesella cincta (L.) and Tomocerus minor (Lubbock) (Collembola) and the role of the coelomoduct kidneys. Comparative Biochemistry and Physiology, 93A, 691-694.

Verhoef, H.A. \& van Selm, A.J. (1983) Distribution and population dynamics of Collembola in relation to soil moisture. Holarctic Ecology, 6, 387-394.

Verhoef, H.A. \& Witteveen, J. (1980) Water balance in Collembola and relation to habitat selection; cuticular water loss and water uptake. Journal of Insect Physiology, 26, 201-208.

White, C.R., Blackburn, T.M., Terblanche, J.S. et al . (2007) Evolutionary responses of discontinuous gas exchange in insects. Proceedings of the National Academy of Sciences of the United States of America, 104, 8357-8361.

Wilson, R.S. \& Franklin, C.E. (2002) Testing the beneficial acclimation hypothesis. Trends in Ecology and Evolution, 17, 66-70.

Zachariassen, K.E. (1996) The water concerving physiological compromise of desert insects. European Journal of Entomology, 93, 359-367.

Zachariassen, K.E., Andersen, J., Kamau, J.M.Z. \& Maloiy, G.M.O. (1988) Water loss in insects from arid and humid habitats in East Africa. Acta Entomologica Bohemoslovaca, 85, 81-93.

Accepted 13 May 2009

First published online 18 August 2009 